\title{
DAYA TAHAN HIDUP BENIH IKAN NILA (Oreochromis niloticus) DALAM PENGANGKUTAN MENGGUNAKAN GALON AIR
}

\author{
(Survival Rate Of Nile Tilapia (Oreochromis niloticus) \\ In Transportation Using A Water Gallon) \\ Restu Yuda Bakrie dan Siky Olgani \\ Fakultas Perikanan Universitas Kristen Palangka Raya \\ Jl. RTA. Milono Km. 8,5 Palangka Raya \\ e-mail: restului@gmail.com
}

Article Submitted: $28-08-2020$

Article Accepted: 17-09-2020

\begin{abstract}
This research was conducted since departing from BBI Gohong to Tewang Rangkang village with a travel time of 5 hours 10 minutes by land transportation. The purpose of this study was to determine the survival (survival rate) of tilapia fry $2-3 \mathrm{~cm}$ in size when transported using a gallon container of water with a density of 280 heads/gallons without being given pure oxygen. The experiment used a completely randomized design with 3 treatments and 3 replications. The results showed that the survival rate (SR) of tilapia fry after transportation showed very significant differences $(\mathrm{P}>0.01)$. The highest $\mathrm{SR}$ at treatment $\mathrm{C}=100 \%$ (transport using plastic bags filled with pure water and oxygen with a ratio of 1: 2 with 280 stocking density). While the lowest SR at Treatment B $=84.76 \%$ At the density level of 280 fish seeds (fry) / 10 liters of water without the addition of oxygen.
\end{abstract}

Keyword: Survival rate, transportation, water gallon

\section{PENDAHULUAN}

Distribusi benih ikan dari pusat pembenihan (hatchery) ke lokasi pembesaran merupakan salah satu kegiatan yang sangat penting dalam budidaya ikan. Permintaan benih ikan dari tempat usaha pembesaran ikan dengan jarak yang jauh memerlukan wadah pengangkutan benih yang dapat menjamin kelangsungan hidup ikan sampai tujuan dengan aman.

Transportasi ikan hidup diartikan sebagai suatu tidakan memindahkan ikan dari tempat ketempat lain dengan memberi perlakuan tertentu untuk menjaga ikan tertebut dapat bertahan hidup sampai ketempat tujuan. Menurut Wibowo (1993), pengangkutan ikan dengan sistim basah dapat dilakukan dengan dua cara, yaitu sistim terbuka dan tertutup.
Selama ini pengangkutan benih ikan dilakukan dengan menggunakan kantong plastik dengan ketebalan $0,08 \mathrm{~mm}$ yang diisi air dan oksigen dengan perbandingan 1:2 kemudian ditempatkan dalam boxs stirofoam agar lebih aman. Namun yang jadi permasalahan di tempat pembenihan kerap tidak tersedia oksigen sebagai penentu utama dalam pengangkutan benih ikan. Sebab itu perlu dicari alternatif baru cara mengangkut benih ikan dengan wadah tanpa harus menggunakan oksigen, namun dapat menjamin kelangsungan hidup benih (survival rate), sehingga selama transportasi dengan jarak yang cukup jauh dan waktu yang cukup lama tidak menyebabkan mortalitas benih yang besar karena perubahan kualitas air (terutama oleh kekurangan oksigen) selama pengangkutan. 
Transportasi ikan hidup pada dasarnya adalah menempatkan hasil perikanan tersebut pada satu lingkungan yang berbeda dengan lingkungan asalnya (kolam) disertai dengan perubahan-perubahan sifat lingkungan yang relatif sangat mendadak, seperti wadah dan goncangan alat transportasi, metabolisme ikan lebih cepat sehingga terjadi perubahan kualitas air seperti suhu, oksigen terlarut (DO), keasaman air $(\mathrm{pH}), \mathrm{CO}_{2}$ dan amoniak $\left(\mathrm{NH}_{3}\right)$ (Suryanti , 1998).

Menurut Jangkaru (1999) secara garis besar pengangkutan ikan hidup dibagi dalam sistem terbuka dan sistem tertutup. Pada sistem terbuka, ikan yang diangkut berhubungan langsung dengan udara bebas. Sebaliknya pada pengangkutan sistem tertutup selama pengangkutan ikan hanya berhubungan dengan udara didalam wadah saja. Selanjutnya (Otomo, 2003) menyatakan bahwa pengangkutan ikan hidup pada dasarnya adalah menempatkan ikan pada suatu lingkungan yang berbeda dengan lingkungan asalnya, dengan perbedaan sekecil mungkin agar ikan yang diangkut dapat hidup sampai ke tempat tujuan atau paling tidak memperkecil tingkat kematian selama pengangkutan.

Pada pengangkutan ikan hidup, beberapa hal yang harus diperhatikan (Anwar, 1989), yaitu: meningkatkan suplai oksigen dengan cara menggantikan udara dengan oksigen murni, meningkatkan tekanan oksigen pada wadah, dan mengurangi konsumsi oksigen rata-rata, mengontrol metabolisme dengan cara mengurangi laju buangan hasil metabolisme.

Menurut Ismi et al.,(2016), Kualitas air media pengiriman harus dijaga agar tetap sesuai bagi kehidupan ikan, khususnya oksigen. Faktor yang sangat penting pada pengangkutan ikan adalah tersedianya oksigen terlarut yang cukup memadai.

Salah satu cara untuk menurunkan tingkat metabolisme ikan adalah dengan cara memberoknya sebelum diangkut (Purnafaningsih, 1998). Ikan akan mempunyai daya tahan hidup lebih baik saat diangkut kalau perutnya kosong, karena itu ikan tidak diberi makan/dipuasakan 1-2 hari sebelum diangkut (Anonim, 2008).

Berdasarkan pengalaman penulis tahun 2019, pernah mengangkut benih ikan gurami (Ospronemus guramy) dengan cara sistim terbuka, yaitu dengan menggunakan wadah galon air minum diisi 15 liter air dan benih ukuran (standar lengh) $1-2 \mathrm{~cm}$ sebanyak 486 ekor dengan waktu transportasi darat 10 Jam, tidak satupun benih mengalami mortalitas. Dengan pengalaman tersebut peneliti mencoba mengangkut benih ikan nila dari BBI Gohong Kabupaten Pulang Pisau ke desa Tewang Rangkang Kabupaten Katingan dengan waktu Tempuh sekitar 5 jam melalui jalan darat.

Ikan Nila (Oreochromis niloticus) adalah salah satu jenis ikan air tawar yang paling banyak dibudidayakan di Indonesia, karena dagingnya cukup tebal dan rasanya sangat gurih. Menurut Suyanto (2003), ikan nila hidup diperairan tawar seperti sungai, danau, waduk dan rawa. Ikan nila dapat hidup diperairan yang dalam dan luas maupun di kolam yang sempit dan dangkal dengan kisaran kadar garam 0-35 permil; Suhu optimal untuk ikan nila yakni berkisar 25-30 $0^{\circ}$.

Menurut Berka (1986), pengangkutan dengan jarak yang lebih jauh biasanya digunakan sistem tertutup, cara yang paling sederhana adalah dengan menggunakan kantong plastik yang diisi air dan oksigen yang diikat rapat. Jumlah ikan yang diangkut tergantung pada ukuran ikan, jenis alat angkut dan lama waktu pengangkutan.

Kepadatan ikan yang tinggi dalam pengangkutan menyebabkan semakin meningkatnya kompetisi ruang gerak dan aktivitas tersebut membutuhkan energi. Meningkatnya kebutuhan energi menyebabkan laju metabolisme meningkat, peningkatan laju metabolisme pada ikan akan menyebabkan semakin memperbanyak produk buangan seperti $\mathrm{NH}_{3}$ dan $\mathrm{C}_{2} \mathrm{O}$ bebas. 
Produk buangan metabolisme tersebut dalam konsentrasi tinggi merupakan racun bagi ikan yang dapat menyebabkan ikan stres dan pada akhirnya dapat menyebabkan kematian ikan. Selain itu juga, kekurangan oksigen mungkin terjadi bila kepadatan ikan demikian tinggi atau waktu angkut lebih lama dari yang ditentukan, Evi Liviawaty dan Afrianto (1990) mengatakan bahwa goncangan positif yaitu membantu difusi oksigen kedalam air.

Penelitian ini bertujuan untuk mengetahui sintasan (SR) benih ikan nila bila diangkut tanpa tambahan oksigen murni dan menemukan cara baru yang dapat di aplikasikan oleh petani ikan dalam hal mengangkut benih ikan (terutama benih ikan nila) tanpa harus tergantung ketersediaan oksigen murni yang kadang susah didapat.

\section{METODE PENELITIAN}

\section{Lokasi dan waktu}

Penelitian ini dilaksanakan selama pengangkutan dari Balai Benih Ikan (BBI) Gohong, Kabupaten Pulang Pisau menuju ke Desa Tewang Rangkang, Kabupaten Katingan dengan waktu tempuh \pm 5 jam melalui jalan darat.

\footnotetext{
Alat dan bahan

Peralatan dan bahan yang digunakan dalam kegiatan penelitian ini adalah: mobil pick up sebagai sarana transportasi, galon air minum volume 19 liter, kantong plastik, termometer suhu, $\mathrm{pH}$ meter, DO meter. Bahan yang digunakan yaitu air sebagai media hidup, benih ikan nila ukuran $1-2$ $\mathrm{cm}$; oksigen murni.
}

\section{Rancangan Penelitian}

Penelitian ini dilakukan dengan metode percobaan (experimental design), menggunakan rancangan acak lengkap (RAL) dengan tiga perlakuan dan tiga ulangan, sebagai berikut:

- Perlakuan A: Galon diisi air 14 liter dengan benih ikan nila 280 ekor

- Perlakuan B : Galon diisi air 10 liter dengan benih ikan nila 280 ekor

- Perlakuan C (kontrol) : Kantong plastik diisi air 10 liter + oksigen murni benih ikan nila 280 ekor.

\section{Tahapan Penelitian:}

1. Pengumpulan benih yang sehat ditandai oleh benih berenang secara aktif

2. Melakukan Pemberokan selama 48 Jam, bertujuan mengeluarkah feses

3. Pengisian air dalam galon dan ikan sesuai perlakuan (tanpa penambahan oksigen murni) tanpa ditutup

4. Pengisian air dan ikan dalam kantong kemudian dimasukan oksigen murni dan di tutup dengan cara diikat menggunakan karet (Perlakuan kontrol)

5. Pengangkutan dilakukan pada malam hari, yaitu pukul $18.00-23.00$ WIB ( 5 jam)

6. Sampai tujuan: Pengambilan data, meliputi :

a.Pengamatan/perhitungan tingkat survival rate (SR) benih ikan nila

b.Pengukuran kualitas air 


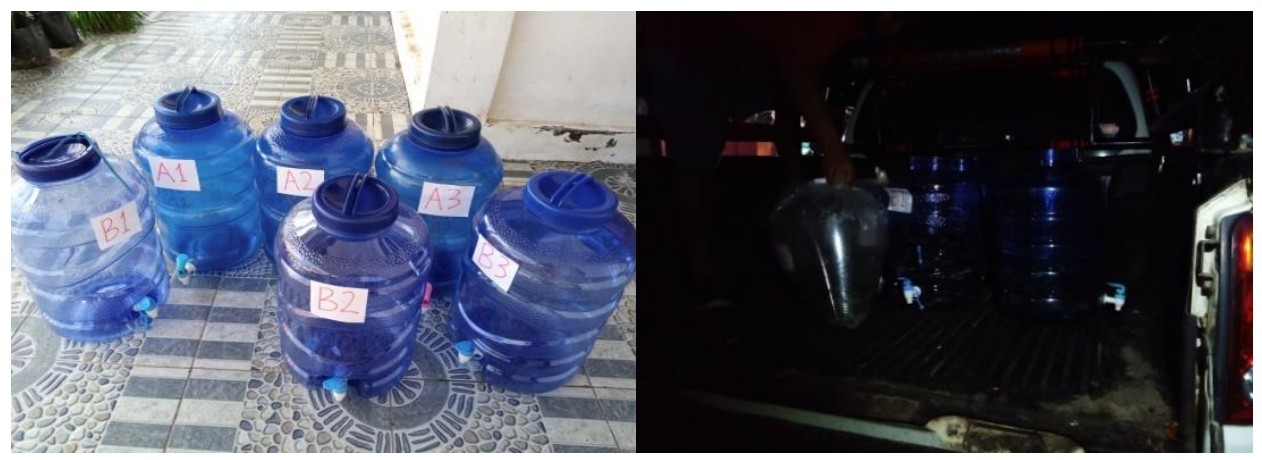

Gambar 1. Galon wadah benih ikan nila dan alat transportasi

\section{HASIL DAN PEMBAHASAN}

Berdasarkan hasil pengamatan terhadap daya tahan hidup atau survival rate
(SR) benih ikan nila setelah sampai tujuan, diperoleh data sebagai berikut:

Tabel 1. Jumlah benih ikan nila hidup (ekor) dan Survival Rate (\%) setiap perlakuan dan ulangan

\begin{tabular}{|c|c|c|c|c|c|c|c|}
\hline \multirow{2}{*}{ No } & \multirow{2}{*}{ Perlakuan } & \multicolumn{3}{|c|}{ Ulangan } & \multirow{2}{*}{ Total } & \multirow{2}{*}{ Rerata } & \multirow{2}{*}{$\begin{array}{c}\text { Survival Rate } \\
(\%)\end{array}$} \\
\hline & & 1 & 2 & 3 & & & \\
\hline 1 & A & 248 & 247 & 246 & 741 & 247,0 & 88,21 \\
\hline 2 & B & 229 & 237 & 246 & 712 & 237,3 & 84,76 \\
\hline 3 & $\mathrm{C}$ & 280 & 280 & 280 & 840 & 280,0 & 100 \\
\hline
\end{tabular}

Sumber: data Primer 2020

Menurut Effendie (2003), untuk menghitung sintasan (SR) dapat digunakan dengan rumus berikut :

$\mathrm{SR}=\frac{\mathrm{Nt}}{\mathrm{No}} x 100 \%$

Keterangan :

SR : derajat kelangsungan hidup

$\mathrm{Nt}$ : jumlah ikan yang hidup pada akhir penelitian (ekor)

No : jumlah ikan yang hidup pada awal penelitian (ekor)

Berdasakan hasil perhitungan survival rate (SR), setiap perlakuan sebagai berikut: Perlakuan A: SR $=\frac{741}{840} x 100 \%=88,21 \%$ Perlakuan B: SR $=\frac{712}{840} x 100 \%=84,76 \%$ Perlakuan C: $\mathrm{SR}=\frac{840}{840} x 100 \%=100 \%$ Berdasarkan hasil perhitungan tersebut terlihat bahwa pada perlakuan $\mathrm{C}$ tidak terjadi mortalitas atau tingkat SR $100 \%$, benih ikan masih lincah berenang secara aktif. Hal ini diduga karena ketersediaan oksigen dan suhu dalam kantong plastik pengangkutan masih mencukupi untuk kebutuhan benih ikan. sedangkan pada perlakuan A: benih ikan nila dapat bertahan hidup (SR) sebesar 88,21\% atau terjadi mortalitas sebesar $11,79 \%$; dan pada perlakuan B benih ikan nila dapat bertahan hidup (SR) sebesar 84,76\% atau terjadi terjadi mortalitas sebesar 15,24\%.

Hasil analisis keragaman (ANOVA) tingkat kelangsungan hidup benih ikan nila pada setiap perlakuan selama pengangkutan menunjukan perbedaan yang sangat nyata, dimana $\mathrm{F}$ hitung $=61,41>\mathrm{F}$ tabel $1 \%=$ 10,92. Hal ini berarti bahwa Tingkat kelangsungan hidup benih ikan nila selama pengangkutan \pm 5 jam diantara perlakuan berbeda sangat nyata. Untuk perlakuan A (wadah galon) yang diisi air sebanyak 14 liter dengan padat benih 280 ekor/galon diperoleh tingkat daya tahan hidupnya sebesar 88,21\%; Perlakuan B (wadah 
galon) yang diisi air sebanyak 10 liter dengan padat benih 280 ekor/galon diperoleh tingkat daya tahan hidupnya sebesar 84,8\%; sedangkan Perlakuan C (wadah kantong plastik: air $10+$ oksigen murni 1:2) dengan padat benih 280 ekor/kantong plastik daya tahan hidupnya $100 \%$.

Berdasarkan hasil uji beda nyata terkecil (BNT) diperoleh nilai sebesar 10,57 hal in berarti bahwa rerata benih ikan nila yang dapat bertahan hidup pada Perlakuan C sebesar 280 ekor berbeda sangat nyata terhdap Perlakuan A (247 ekor) dan Perlakuan B (237 ekor); sedangkan Perlakuan A dan B tidak berbeda nyata. Terjadinya mortalitas pada perlakuan A dan $\mathrm{B}$ ini kemungkinan karena terjadinya penurunan kualitas air di alam galon.

Dilihat kualitas air awal dengan akhir pengangkutan untuk perlakuan $\mathrm{C}$ tidak mengalami penurunan yang siknifikan, seperti suhu awal $27,5^{\circ} \mathrm{C}$ dan akhir $28^{\circ} \mathrm{C}$, hal ini sesuai Anonim (1996), yang menyatakan bahwa suhu air yang berkisar antara $18-28^{\circ} \mathrm{C}$ dipandang memadai untuk mengangkut ikan; pH 6,0 menjadi 6,1 hal ini sesuai dengan pendapat Suseno (1974), yang menyatakan bahwa ikan hanya tahan terhadap pergoncangan $\mathrm{pH}$ antara 5-8 dan jika keadaan ini terpenuhi maka ikan dapat hidup dengan normal; DO (disolved oxygent-ppm) awal 6,5 menjadi 6,4; dan amonik $\mathrm{NH}_{3}$ awal 0,025 menjadi 0,026 . Jadi pengangkutan benih ikan nila dengan waktu tempuh sekitar 5 jam menggunakan wadah galon air minum yang diisi air 15 liter tanpa penambahan oksigen murni, dengan sintasan (SR) $\quad(\mathrm{A}=88,21 \%)$ atau terjadi mortalitas masing-masing perlakuan $\mathrm{A}=11,79 \%$ masih dapat dilakukan. Menurut Perdi A., Rosmawati dan Fia (2016), sintasan (SR) benih ikan nila setelah pengangkutan selama 10 jam sebesar $93,75 \%$ tanpa pemberian terpung gandum pada media air diberi oksigen murni dengan padat tebar sebesar 400 ekor benih ukura 3-4 cm. Besarnya mortalitas benih ini diduga disebabkan karena terjadinya penurunan kualitas air yang cukup siknifikan, seperti suhu awal air dalam galon $28^{\circ} \mathrm{C}$ menjadi 30 ${ }^{\circ} \mathrm{C}$, perubahan suhu dapat meningkatkan laju metabolisme ikan, karena semakin tinggi suhu maka proses metabolime semakin meningkt pula. Suhu yang tinggi dapat meningkatkan konsumsi oksigen, sehingga menurunkan kadar oksigen dalam air media pengakutan. $\mathrm{DO}_{(\mathrm{ppm})}$ awal 4,5 menjadi 1,1 ; $\mathrm{NH}_{3}$ awal 0,0025 meningkat menjadi 0,032., Keberadaan amoniak bergantung pada suhu dan $\mathrm{pH}$, Amoniak yang dihasilkan merupakan hasil eksresi langsung amoniak oleh ikan atau hasil metabolisme ikan (Swan, 1993). Sedangkan $\mathrm{pH}$ air dalam galon pada akhir pengangkutan sebesar 6,5 masih normal. Walaupun terjadi motalitas mencapai $11,795 \%$ pada Perlakuan A, namun cara ini masih dapat diaplikasikan untuk mengangkutan benih ikan, terutama untuk pengangkutan jarak dekat atau waktu pengangkutan kurang dari 5 jam perjalanan.

\section{KESIMPULAN DAN SARAN}

\section{Kesimpulan}

Berdasarkan hasil penelitian bahwa pengangkutan benih ikan nila (Oreochromis niloticus) menggunakan wadah galon dengan lama waktu pengangkutan kurang lebih 5 jam masih dapat diaplikasikan walaupun persentase mortalitas pada wadah galon dalam perlakuan A sebanyak (11,79\%) dengan padat penebaran 280 ekor benih/15 liter air.

\section{Saran}

Apabila ingin mengangkut benih ikan nila menggunakan galon air minum tanpa tambahan oksigen, maka kepadatan benih ikan nila dapat dikurangi dan waktu tempuhnya kurang dari 5 jam.

\section{DAFTAR PUSTAKA}

Anonim, 1996. Cara Pengangkutan Ikan Hidup Dengan Sistem Basah. Balai Penelitian dan Pengembangan Pertanian. Jakarta 
Anonim, 2008. Budidaya Ikan Nila (Oreochromis niloticus). Proyek Pengembangan Ekonomi Masyarakat Pedesaan. BAPPENAS.

Anwar, 1989. Pengangkutan Ikan Hidup. Digilib.unila.ac.id. Diakses tanggal 27 Maret 2020.

Effendie, H 2003. Kualitas air bagi pengelolaan sumberdaya dan lingkungan perairan. Kanisius 2003. 258 hal

Jangkaru, Z. 1999. Petunjuk teknis budidaya ikan nila merah. Seri pengembangan penelitian perikanan, Jawa Tengah 79 hlm.

Liviawaty dan Afrianto, 1990. Pengendalian hama dan Penyakit ikan. Penerbit Kanisius. Yogyakarta. $89 \mathrm{hlm}$.

Perdi A, Rosmawati dan Fia, 2016. Penggunaan tepung gandum sebagai sumber Karbon Pada Pengangkutan Benih Ikan Nila (Oreochromis niloticus). Jurnal Mina Sains, Volume 2 Nomor 1. April 2016.

Pramono, 2002 dalam Ismi et al. 2016. Pengaruh Penggantian Oksigen pada Transportasi Benih. https://media.neliti.com>media.

Diakses tanggal 27 Maret 2020.

Pramono, 2009. Transportasi Ikan Nila. IPB repository. https://repository.ipb.ac.id. Diakses tanggal 27 Maret 2020.

Purfaningsih, S. 1998. Sistem Transportasi Ikan Hidup. Buletin Limnologi Hasil Perikanan Vol. V No.1 Tahun 1998. IPB.

Suyanto, 2003. Pembenihan dan Pembesaran Nila. Penebar Swadaya. Jakarta.

Swann, 1993. Transportation of fish in bags. United states: north central regional aquaculture central. Fact sheet series\# 104 illinois indiana.

Utomo, N.B.P. 2003. Modul Pemanenan dan Pengangkutan ikan, Depdiknas, http://bos.fkip.uns.ac.id/pub/ono/pendi dikan/materi-

kejujuran/pertanian/budidaya ikan air tawar/pembesaran ikan karper pemanenan dan pengangkutan ikan. pdf. Diakses tanggal 27 Maret 2020.

Wibowo, 1993. Penerapan Teknik Penangnan dan Trasportasi ikan Hidup di Indonesia. Sub.BPPL, Slipi Jakarta 